\section{Molecular Encoding at the Nanoscale: From Complex Cubes to Bimetallic Oxides**}

\author{
Sebastian Polarz, * Andrey V. Orlov, \\ Maurits W. E. van den Berg, and Matthias Driess
}

Nanoparticles, ${ }^{[1,2]}$ in particular those of semiconducting metal oxides like $\mathrm{ZnO}$, have received increasing attention because of their high potential as components in nanotechnological devices. In general, materials containing more than one type of metal should display higher complexity and a wider range of properties. ${ }^{[3]}$ So far only little attention has been paid to bior multimetallic oxide nanostructures, although a diverse spectrum of properties can be envisioned for such oxides. ${ }^{[4]}$ Multimetallic oxides have been known in solid-state chemistry for a long time, but the high processing temperatures typically applied make them less suitable for the preparation of nanoscaled materials. ${ }^{[5]}$ In addition, optimum dispersity of the two metals inside the nanostructures would play a pivotal role for the rational synthesis and adjustment of properties of those systems. Optimum dispersity is ensured when the respective elements are distributed on the molecular level. ${ }^{[6]}$ In this respect, the use of molecular single-source precursors could potentially solve this problem by the creation of molecular building blocks suitable for bottom-up formation of oxides or other materials. Correlated to the molecular design of the precursor are low thermolysis temperatures resulting in reduced particle growth. ${ }^{[7]}$ However, the preparation of a specific precursor resulting in a specific oxide is difficult, ${ }^{[8]}$ especially if bi- or multimetallic oxide nanostructures are targeted. ${ }^{[4,9]}$ Some examples for such single-source precursors exist already. ${ }^{[10-16]}$ In most cases these heterometallic precursors are alkoxides and are thus very moisture sensitive. ${ }^{[17-19]}$

Our goal is to identify a new precursor system that enables access to a large variety of nanoscaled bimetallic oxides, and at the same time is readily available and stable. One particular type of bimetallic oxide of current interest is metal oxide semiconductors (for instance $\mathrm{ZnO}$ ) doped with paramagnetic metal ions like $\mathrm{Mn}^{2+}$ and $\mathrm{Ni}^{2+}$. Since such metal-doped oxides

[*] Dr. S. Polarz, A. V. Orlov, Prof. Dr. M. Driess

Institute of Chemistry

Technical University Berlin

Strasse des 17. Juni 135, 10623 Berlin (Germany)

Fax: (+49) 30-314-29732

E-mail: sebastian.polarz@tu-berlin.de

Dr. M.W. E. van den Berg

Department of Chemistry

Ruhr-University Bochum

Universitätsstrasse 150, 44780 Bochum (Germany)

[***] S.P. gratefully acknowledges funding from the DFG (Emmy-Noether program). We thank W. Grünert for valuable discussions. Supporting information for this article is available on the WWW under http://www.angewandte.org or from the author. are expected to display considerable magnetoresistivity, they are promising materials for "spintronics". ${ }^{[20,21]}$ Heterometallic precursors for this type of materials are currently unknown.

Herein, we report on the intriguing properties of molecular clusters having heterocubane architecture $\left.\left[\mathrm{M}_{4-y}^{1} \mathrm{M}_{y}^{2}(\mathrm{LH})_{4}\right]^{4+}(\mathrm{OAc})_{4-x}\left(\mathrm{ClO}_{4}\right)_{x} \cong \quad \cong \quad \mathrm{M}_{4-y}^{1} \mathrm{M}_{y}^{2} \mathrm{O}_{4}\right] ; \quad$ see Scheme 1) with a singly deprotonated dipyridyldiol (LH) as a chelating ligand, and their exploitation for the preparation of metal-doped transition-metal oxides. We show that 1) monometallic $\left[\mathrm{M}_{4} \mathrm{O}_{4}\right]$ clusters are single-source precursors for nanoscaled oxides; 2) any combination and permutation of bimetallic clusters $\left[\mathrm{M}_{4-y}^{1} \mathrm{M}_{y}^{2} \mathrm{O}_{4}\right]$ containing the metals $\mathrm{M}^{1,2}=$ $\mathrm{Mn}, \mathrm{Co}, \mathrm{Ni}, \mathrm{Zn}$ are easily accessible; and 3 ) these bimetallic clusters can be used to prepare nanoscaled bimetallic oxides. The oxo clusters introduced here are the smallest possible molecular building blocks for the desired bimetallic oxide nanostructures (see Scheme 1).

1) Preparation of nanoscaled oxides from $\left[\mathrm{M}_{4} \mathrm{O}_{4}\right]$ precursors. In order to probe the capacity of the described clusters as reliable precursors, the thermolysis behavior of the different monometallic compounds $\left[\mathrm{M}_{4} \mathrm{O}_{4}\right]$ was studied by thermogravimetric analysis (TGA) and powder $\mathrm{X}$-ray diffraction (PXRD). The data for the $\left[\mathrm{Zn}_{4} \mathrm{O}_{4}\right]$ cluster shown in Figure 1 are representative. Since phase-pure zinc oxide is obtained both under argon as well as under oxidative $\left(20 \mathrm{vol} \% \mathrm{O}_{2}\right)$ conditions as proven by PXRD, $\left[\mathrm{Zn}_{4} \mathrm{O}_{4}\right]$ is a suitable singlesource precursor for $\mathrm{ZnO}$. The presence of oxygen facilitates the complete removal of the organic ligands as proven by TG analysis. Apart from the fact that one can obtain nanocrystalline $\mathrm{ZnO}$, it is also possible to control the size of the $\mathrm{ZnO}$ particles by heating the $\left[\mathrm{Zn}_{4} \mathrm{O}_{4}\right]$ precursor to a particular temperature $T_{\mathrm{d}}$ and maintaining this temperature for $3 \mathrm{~h}$ in order to oxidize off the organic shell. Under these conditions, the size of the $\mathrm{ZnO}$ particles (determined by the Scherrer equation) depends nearly linearly on the thermolysis temperature $T_{\mathrm{d}}$ (similar to the $\mathrm{Ni}-\mathrm{ZnO}$ system shown below). Similar behavior was found for the alternative monometallic precursors with the difference that the oxidation state of the resulting materials may be sensitive to the presence of oxygen during thermolysis [Eq. $(1 \mathrm{a}-\mathrm{d})]$. Oxidizing conditions were selected for the preparation of bimetallic oxides.

$$
\begin{aligned}
& \mathrm{Zn}^{\mathrm{II}} \mathrm{O} \stackrel{\text { ox. }}{\longleftarrow}\left[\mathrm{Zn}_{4} \mathrm{O}_{4}\right] \stackrel{\text { inert }}{\longrightarrow} \mathrm{Zn}^{\text {II }} \mathrm{O} \\
& \mathrm{Co}^{\mathrm{II}} \mathrm{O} \stackrel{\text { ox. }}{\longleftarrow}\left[\mathrm{Co}_{4} \mathrm{O}_{4}\right] \stackrel{\text { inert }}{\longrightarrow} \mathrm{Co}^{\mathrm{II}} \mathrm{O} \\
& \mathrm{Mn}_{2}^{\text {III }} \mathrm{O}_{3} \stackrel{\text { ox. }}{\longleftarrow}\left[\mathrm{Mn}_{4} \mathrm{O}_{4}\right] \stackrel{\text { inert }}{\longrightarrow} \mathrm{Mn}^{\text {II }} \mathrm{O} \\
& \mathrm{Ni}^{\mathrm{II}} \mathrm{O} \stackrel{\text { ox. }}{\longleftarrow}\left[\mathrm{Ni}_{4} \mathrm{O}_{4}\right] \stackrel{\text { inert }}{\longrightarrow} \mathrm{Ni}^{0}
\end{aligned}
$$

2) Preparation of bimetallic heterocubanes $\left[\mathrm{M}_{4-\mathrm{y}}^{1} \mathrm{M}_{\mathrm{y}}^{2} \mathrm{O}_{4}\right]$ as precursors. Instead of employing pure metal acetates in the synthesis of the single-metal clusters, we used mixtures of metal acetates in order to synthesize bimetallic heterocubanes, which were hitherto unknown (Scheme 1). In fact, we could prepare all possible combinations and permutations of the mixed bimetallic clusters $\left[\mathrm{M}_{4-y}^{1} \mathrm{M}_{y}^{2} \mathrm{O}_{4}\right]\left(\mathrm{M}^{1,2}=\mathrm{Mn}, \mathrm{Co}, \mathrm{Ni}\right.$, $\mathrm{Zn}$; see Scheme 1) in single-crystalline form (see the Supporting Information). Because of the cationic character of the 


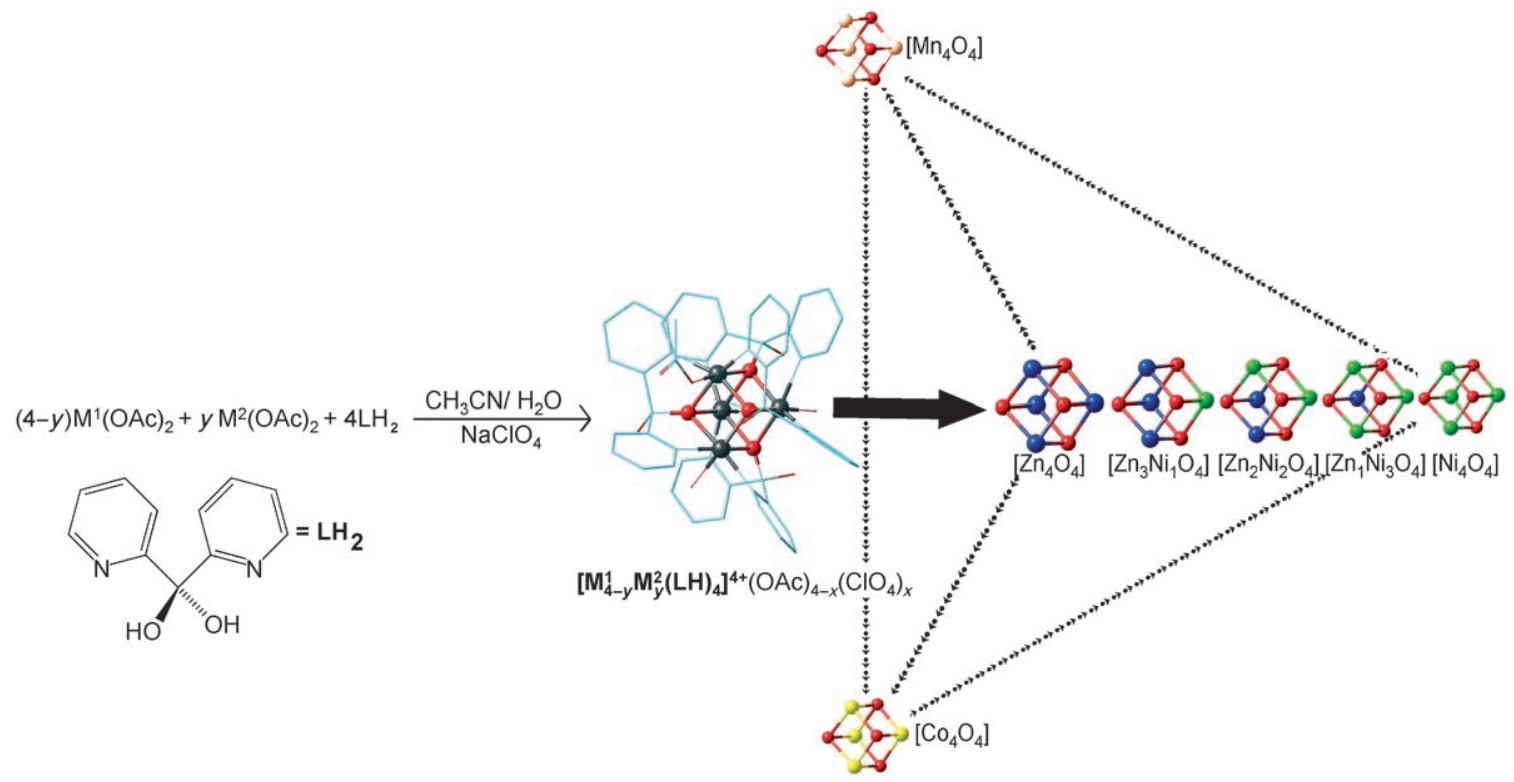

Scheme 1. Possible combinations and permutations of metals in bimetallic clusters. The chemical equation describes the general synthetic route to the heterometallic clusters. The central $\mathrm{M}_{4} \mathrm{O}_{4}$ motif is highlighted in the structural plot. (A structure determined by single-crystal X-ray analysis is shown in the Supporting Information.) The tetrahedron on the right outlines the possibilities for accessible precursor systems: monometallic clusters are located at the corners, bimetallic clusters along the edges, and trimetallic clusters (not shown) along the faces.

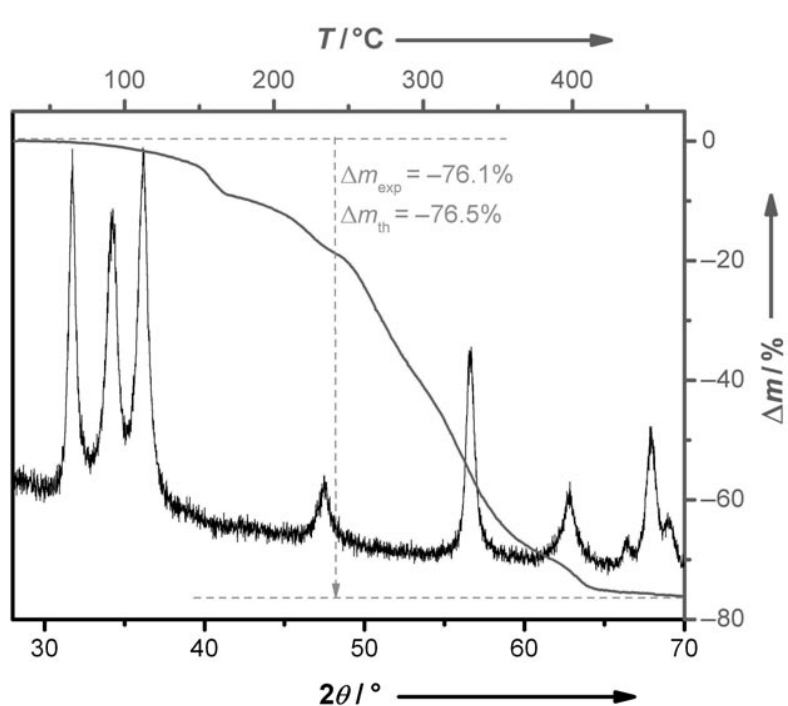

Figure 1. Powder $\mathrm{X}$-ray diffraction pattern for the thermolyzed $\left[\mathrm{Zn}_{4} \mathrm{O}_{4}\right]$ cluster (black) and the thermogravimetric trace (gray) for its thermolysis. It is seen that the experimentally observed mass loss is very close to the theoretical mass loss for the transformation to $\mathrm{ZnO}$

oxo cluster core, the formation of the molecules can be followed by electrospray ionization mass spectrometry (ESIMS). The spectra were recorded for acetonitrile solutions obtained from dissolving exactly one single crystal. ESI-MS gives a reliable picture of the true compositional distribution of the obtained clusters. The results are shown for the combinations $\mathrm{Zn} / \mathrm{Ni}, \mathrm{Zn} / \mathrm{Co}$, and $\mathrm{Co} / \mathrm{Ni}$ as proof of principle (Figure 2). The most intensive signals in the spectra can be attributed to cluster ions of the type $\left[\mathrm{M}_{4-y}^{1} \mathrm{M}_{y}^{2}(\mathrm{LH})_{2}(\mathrm{~L})_{2}\right]^{2+}$ (denoted as $\left[\mathrm{M}_{4-y}^{1} \mathrm{M}_{y}^{2} \mathrm{O}_{4}\right]^{2+}$ ). Here, all counterions are solvent separated, but two dipyridyldiol functions in the cluster cations are additionally deprotonated, resulting in a net charge of +2 . Signals related to singly charged species and complexes with different ratios of perchlorate to acetate were also seen in the spectra, but we focussed on the most intensive signal mentioned above. A broad signal centred around $\mathrm{m} / \mathrm{z}, 550$ was observed (Figure $2 \mathrm{a}$ ) when the synthesis mixture with the molar ratio of $\mathrm{Zn}^{2+} / \mathrm{Ni}^{2+}=3: 1$ was used. If one calculates the theoretical pattern expected for different cluster compositions, this signal is found to correspond to a superposition of several species. Deconvolution of the signal indicates that the solution contains roughly $73 \%\left[\mathrm{Zn}_{3} \mathrm{NiO}_{4}\right]^{2+}$ as well as $22 \%\left[\mathrm{Zn}_{4} \mathrm{O}_{4}\right]^{2+}$ and $5 \%\left[\mathrm{Zn}_{2} \mathrm{Ni}_{2} \mathrm{O}_{4}\right]^{2+}$. This is not surprising since the formation of clusters of different compositions is entropically favored. We also checked that there is no interchange equilibrium in solution. Pure $\left[\mathrm{Zn}_{4} \mathrm{O}_{4}\right]$ and pure $\left[\mathrm{Ni}_{4} \mathrm{O}_{4}\right]$ were dissolved together, and the ESI mass spectrum was recorded after two weeks. No formation of mixed clusters was found under these conditions. This and the fact that we used only one single crystal for each solution for ESI-MS measurement is clear proof that the bimetallic clusters are not an artifact but that they exist in solution as well as in the solid state.

Similarly, for the molar ratio $\mathrm{Zn}^{2+} / \mathrm{Co}^{2+}=1: 1$ (Figure $2 \mathrm{~b}$ ) not only the expected $\left[\mathrm{Zn}_{2} \mathrm{Co}_{2}\right]^{2+}$ but also the other permutations $\left(\left[\mathrm{Co}_{4} \mathrm{O}_{4}\right]^{2+},\left[\mathrm{ZnCo}_{3} \mathrm{O}_{4}\right]^{2+},\left[\mathrm{Zn}_{3} \mathrm{CoO}_{4}\right]^{2+}\right)$ are observed in lower amounts as well. In principle all combinations of mixed-metal clusters $\left(\mathrm{M}^{1,2}=\mathrm{Mn}, \mathrm{Co}, \mathrm{Ni}, \mathrm{Zn}\right)$ can be obtained. This is shown for the formation of mixed clusters starting from the molar ratio $\mathrm{Ni}^{2+} / \mathrm{Co}^{2+}=1: 1$ (Figure 2c). However, for addressing the mixed-metal clusters as precursors it would be even more desirable if one could obtain only one molecular species instead of a mixture of cluster compounds. To investigate this, the $\mathrm{Zn} / \mathrm{Ni}$ system was chosen as a model 

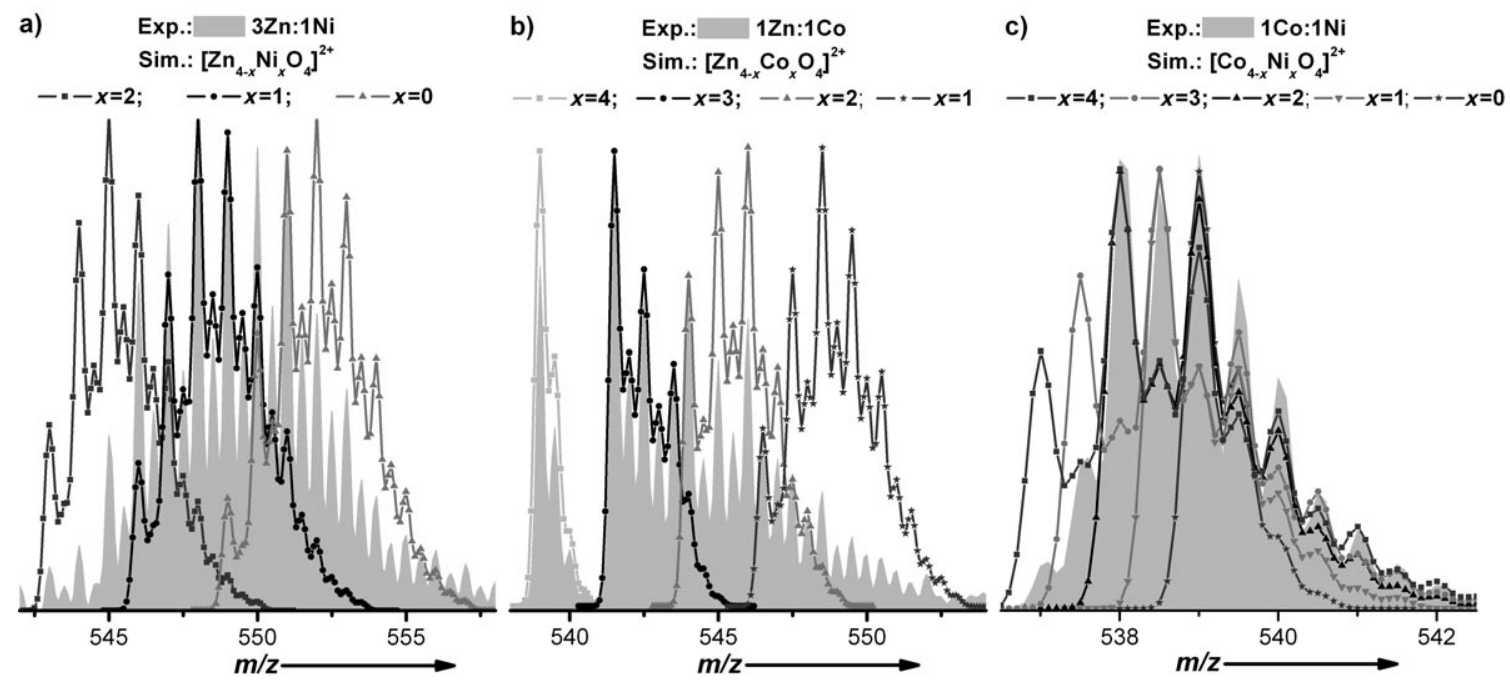

Figure 2. ESI mass spectra of mixed-metal clusters: a) $\mathrm{Zn} / \mathrm{Ni}$, b) $\mathrm{Zn} / \mathrm{Co}$, and c) $\mathrm{Co} / \mathrm{Ni}$. The light gray areas represent the measured spectra (Exp.), while the straight lines with symbols show the simulated patterns for a particular cluster composition (Sim.).

system. By changing the initial molar ratios of metal ions $\mathrm{Zn}^{2+} / \mathrm{Ni}^{2+}$ from $3: 1$ to $1: 1$ (Figure $3 \mathrm{a}$ ), the center of the cluster distribution can be moved towards clusters containing more $\mathrm{Ni}$ (cf. Figure $2 \mathrm{a}$ ) but the width of the distribution is not affected.

Because the clusters are well soluble in acetonitrile as well as in water, we investigated whether the clusters of different compositions can be separated by chromatography. We performed HPLC on silica gel with a sodium acetate buffer as eluent. Indeed, fractions were collected with a narrower distribution of clusters (Figure $3 \mathrm{~b}$ ). The resulting pattern shows very good agreement with the pattern expected for a pure $\left[\mathrm{Zn}_{3} \mathrm{NiO}_{4}\right]^{2+}$ cluster (see Figure 2a).

3) Preparation of bimetallic oxide nanoparticles from mixed-metal clusters. The pure $\left[\mathrm{Zn}_{3} \mathrm{NiO}_{4}\right]$ compound obtained after chromatography was further used for the synthesis of oxidic materials. The formation of a nickel-doped zinc oxide is further complicated by the different coordination geometries (tetrahedral for $\mathrm{Zn}^{2+}$ in $\mathrm{ZnO}$; octahedral for $\mathrm{Ni}^{2+}$ in NiO). Thermodynamically, this leads to a positive free mixing enthalpy. The formation of a spinell could be an alternative to the demixing, but spinells are not known for the $\mathrm{Ni} / \mathrm{Zn} / \mathrm{O}$ system. It is thus expected that for thermolysis of the $\left[\mathrm{Zn}_{3} \mathrm{NiO}_{4}\right]$ precursor demixing occurs resulting in a "zincsaturated" $\mathrm{NiO}$ phase and a "nickel-saturated" $\mathrm{ZnO}$ phase. This is indeed the case as can seen from the XRD pattern of a sample where $\left[\mathrm{Zn}_{3} \mathrm{NiO}_{4}\right]$ had been decomposed at $T=500^{\circ} \mathrm{C}$ and tempered at this temperature for three hours (Figure $4 \mathrm{a}$ ). The reflections can be attributed to $\mathrm{Ni}_{0.7} \mathrm{Zn}_{0.3} \mathrm{O}$ (particle diameter $D_{\mathrm{p}}=44.1 \mathrm{~nm}$ ) and $\mathrm{ZnO}$. The formation of the known $\mathrm{Ni}_{0.7} \mathrm{Zn}_{0.3} \mathrm{O}$ phase is also very reasonable as $\mathrm{Zn}^{2+}$ can easily adopt octahedral coordination.

If, on the other hand, the precursor is thermolyzed at lower temperature, smaller particles result. It was already mentioned that under the described conditions the relationship between $T_{\mathrm{d}}$ and the particle size is practically linear (Figure $4 \mathrm{c}$ ). Thus, particle size can be adjusted to a certain extent. Particles resulting from $T_{\mathrm{d}}=250^{\circ} \mathrm{C}$ are only $10.1 \mathrm{~nm}$
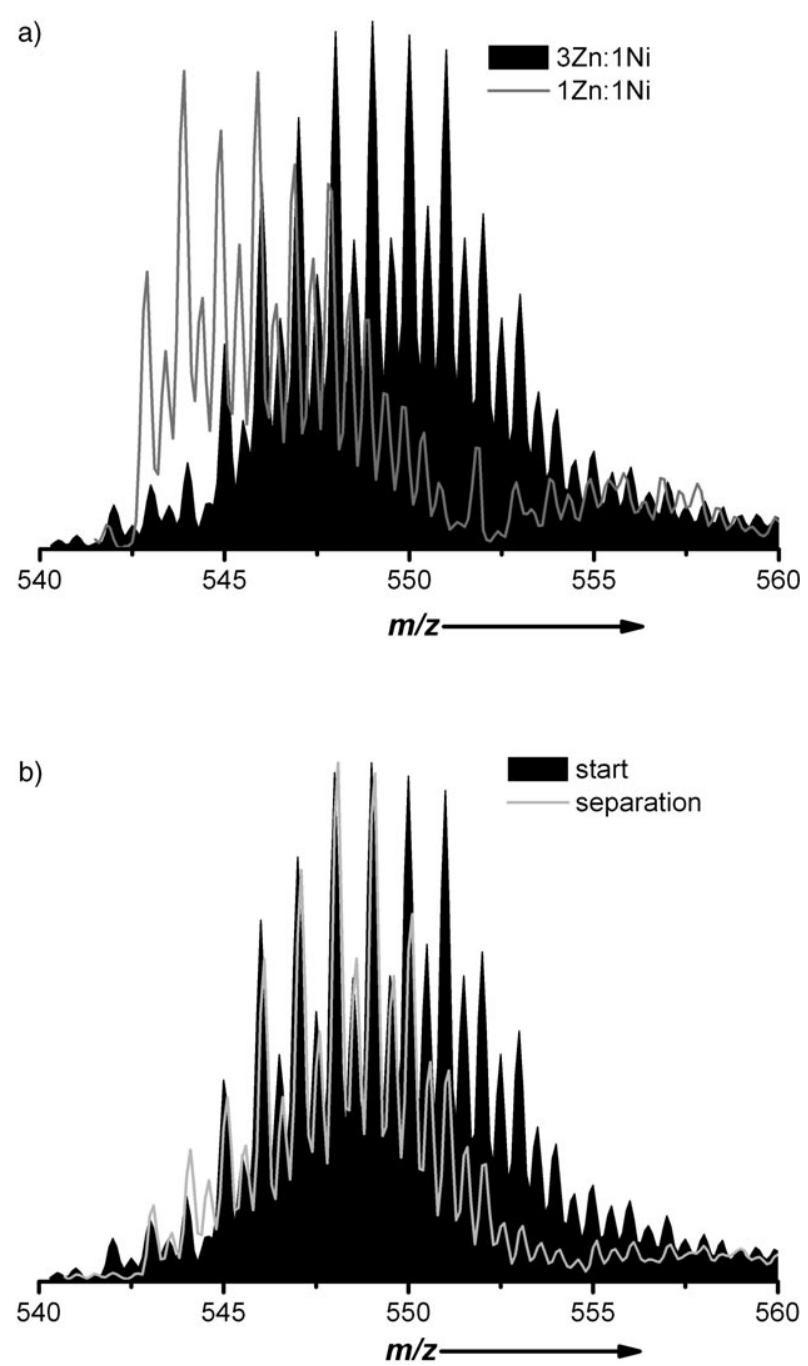

Figure 3. Change of the distribution of mixed $\mathrm{Zn} / \mathrm{Ni}$ clusters from the initial distribution (black curve) a) upon adjustment of the initial ratio of metal acetates (gray line) and b) after chromatographic separation (gray line). 


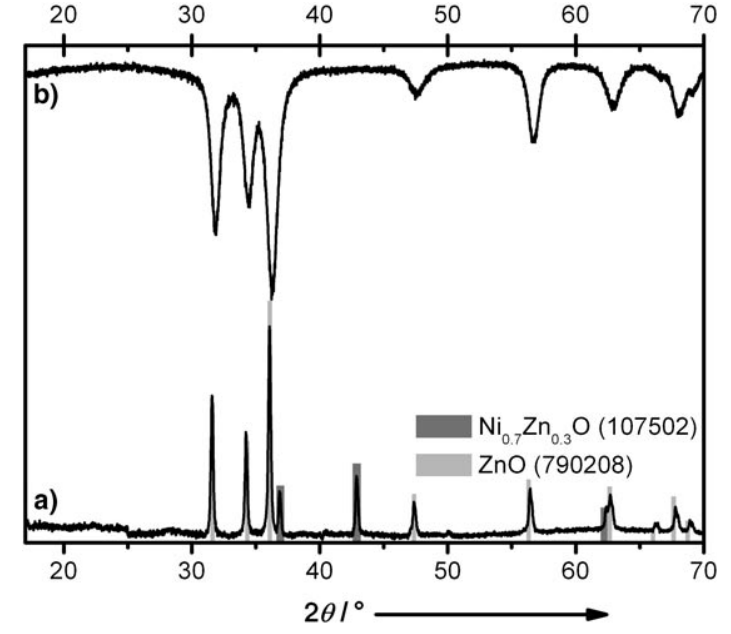

c)

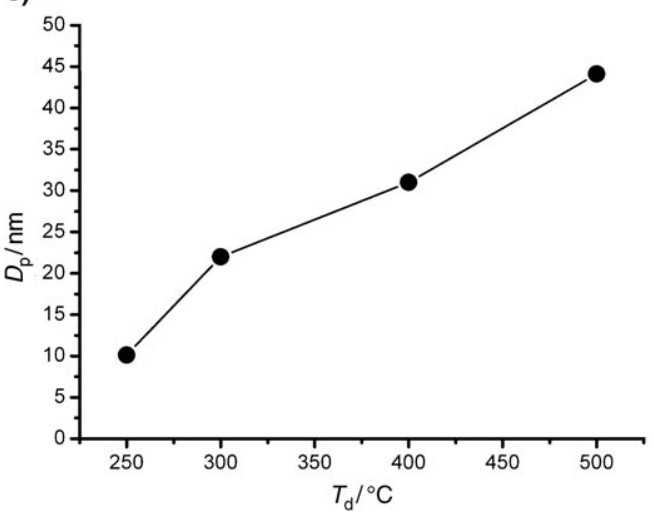

Figure 4. Powder $\mathrm{X}$-ray diffraction patterns for material obtained by decomposition of $\left[\mathrm{Zn}_{3} \mathrm{Ni}\right]$ at a) $T_{\mathrm{d}}=500^{\circ} \mathrm{C}$ and b) $T_{\mathrm{d}}=250^{\circ} \mathrm{C}$. c) Dependence of particle size on decomposition temperature.

in size. Surprisingly, only the reflections of $\mathrm{ZnO}$ are found for the small particles, and a $\mathrm{NiO}$ phase is not detectable by X-ray diffraction (Figure 4b). EDX spectra (see the Supporting Information) recorded on agglomerates of such particles indicate that these particles contain $\approx 30 \%$ nickel. However, it can not be excluded by EDX alone that the agglomerates do not contain particles of different composition. Nevertheless, TEM images indicate that these agglomerates are not amorphous and that the size of the constituent particles is very similar to that determined by means of X-ray scattering data (see SI2 in the Supporting Information). Therefore, it seems unlikely that an amorphous $\mathrm{NiO}$ phase, which would have been invisible in PXRD, is present in this material.

Another model which, at this point, can also not be excluded is that a thin $\mathrm{NiO}$ layer covers the $\mathrm{ZnO}$ nanoparticles. To consider this possibility in more detail, the local structures of the $\mathrm{Zn}$ and Ni centers were determined from Kedges (at 9659.0 and $8333.0 \mathrm{eV}$, respectively) by X-ray absorption spectroscopy (XAS) for the sample prepared at $T_{\mathrm{d}}=250^{\circ} \mathrm{C}$. Whereas from XRD results it is not possible to exclude small, amorphous $\mathrm{NiO}$ particles dispersed in $\mathrm{ZnO}$, the XAS results indicate that the crystalline environment of $\mathrm{Ni}$ does not permit such an interpretation. The $\mathrm{Ni}-\mathrm{O}$ distance fitted to the first feature in the Fourier transform of $\chi$ was found to be $2.07 \AA$, indicating a coordination number of $\mathrm{Ni}^{2+}$ of the order of 4 . Furthermore, the $\mathrm{Ni}-\mathrm{Ni}$ distance is clearly too small to be explained by the presence of a separate $\mathrm{NiO}$ phase (Figure 5). Small deviations in the Ni X-ray absorption
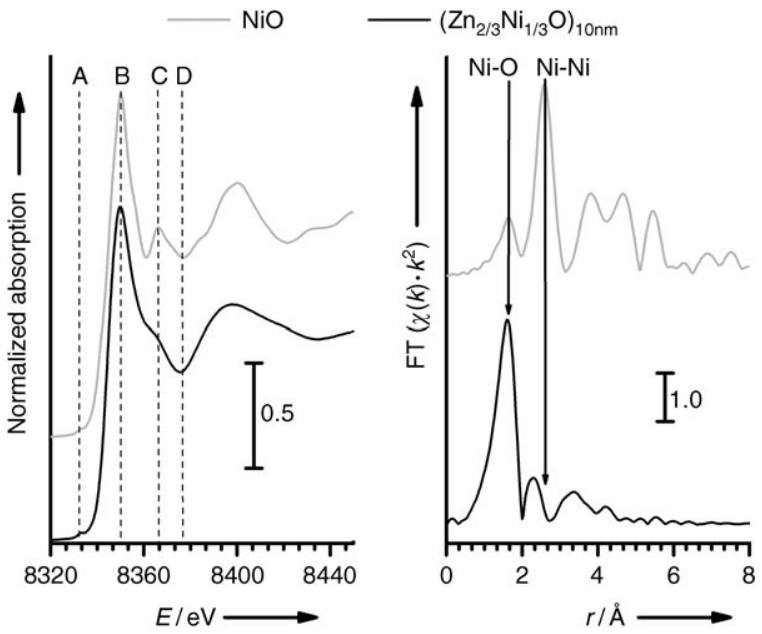

Figure 5. Ni K-edge XAS spectra of $\mathrm{NiO}$ and $\left[\mathrm{Zn}_{3} \mathrm{NiO}_{4}\right]\left(T_{\mathrm{d}}=250^{\circ} \mathrm{C}\right)$. Left: The XANES features A, B, C, and D. Right: The Fourier transform (not corrected for phase shifts).

near-edge spectrum (XANES) confirm this hypothesis. A $\mathrm{NiO}$ layer on top of the $\mathrm{ZnO}$ particles would have given a $\mathrm{Ni}-$ $\mathrm{Ni}$ distance close to the value expected for $\mathrm{NiO}$. Therefore, we propose a model in which $\mathrm{Ni}^{2+}$ centers have replaced $\mathrm{Zn}^{2+}$ in the $\mathrm{ZnO}$ lattice. This assumption is further supported by modeling of the XAS data taking this model into account (see SI3 in the Supporting Information).

If one considers all the data together (the precursor architecture, the mild thermolysis conditions, TEM/EDX, PXRD, EXAFS), it appears that the molecular preorganization determined in $\left[\mathrm{Zn}_{3} \mathrm{NiO}_{4}\right]$ can lead to a Ni-doped $\mathrm{ZnO}$ but only for small particle sizes.

The findings reported here indicate that by forcing matter into the nanoscale, it is not only possible to manipulate the properties of ensembles of atoms (band gap) but also to alter the chemistry of individual atoms. It could be shown as soon as the particles are small enough, the chemical behavior of $\mathrm{Ni}^{2+}$ changes. It was possible to mix two species with each other that normally would segregate (demixing into $\mathrm{ZnO}$ and $\mathrm{NiO}$ ).

The reason for this unusual behavior is presumably very simple. On the nanoscale, the total free energy of a system, $\Delta G_{\text {tot }}$, is increasingly dependent on the free interface energy as particles become smaller, $d G \propto(\partial G / \partial A) \mathrm{d} A$, a relationship well established in colloid science. Thus, for the bulk (large particles) $\Delta G_{\text {tot }}$ is mainly determined by the free mixing energy, $\Delta G_{\text {mix }}$, and free interface energy, $\Delta G_{\text {if }}$, is negligible. However, the situation changes for the nanoscale: $\Delta G_{\text {mix }}$ and $\Delta G_{\text {if }}$ are antidromic in a certain sense. While a positive $\Delta G_{\text {mix }}$ results in demixing and thus the formation of two new particles, the formation of smaller particles from a larger one 
is countered by $\Delta G_{\text {if }}$, which is always positive. Therefore, under conditions where transport of matter is restricted, as under the moderate thermolysis temperatures used here for the preparation of the small oxidic nanoparticles, free interface energy overcompensates the free demixing energy, and thus demixing does not occur. This, in turn, leads to the formation of particles with unusual fine structure, for example, the $\mathrm{ZnO}$ particles doped with high content of tetrahedral $\mathrm{Ni}^{2+}$ atoms. Because the "game" of pitting $\Delta G_{\text {if }}$ against $\Delta G_{\text {mix }}$ is so fundamental, it can certainly be applied to many other systems as well.

Received: April 6, 2005

Revised: September 5, 2005

Published online: November 21, 2005

Keywords: heterocubanes - metal acetates - nanoparticles . transition-metal oxides

[1] J. H. Fendler, F. C. Meldrum, Adv. Mater. 1995, 7, 607.

[2] C. N. R. Rao, G. U. Kulkarni, P. J. Thomas, P. P. Edwards, Chem. Soc. Rev. 2000, 29, 27

[3] N. Toshima, T. Yonezawa, New J. Chem. 1998, 22, 1179.

[4] M. Niederberger, N. Pinna, J. Polleux, A. Antonietti, Angew. Chem. 2004, 116, 2320; Angew. Chem. Int. Ed. 2004, 43, 2270.

[5] M. Jansen, Angew. Chem. 2002, 114, 3896; Angew. Chem. Int. Ed. 2002, $41,3746$.

[6] N. Herron, D. L. Thorn, Adv. Mater. 1998, 10, 1173.

[7] V. Ischenko, S. Polarz, D. Grote, V. Stavarache, K. Fink, M. Driess, Adv. Funct. Mater. 2005, DOI: 10.1002/adfm.200500087.

[8] S. L. Cumberland, K. M. Hanif, A. Javier, G. A. Khitrov, G. F. Strouse, S. M. Woessner, C. S. Yun, Chem. Mater. 2002, 14, 1576.

[9] M. Niederberger, G. Garnweitner, N. Pinna, M. Antonietti, J. Am. Chem. Soc. 2004, 126, 9120.

[10] S. Mathur, M. Veith, M. Haas, A. Shen, N. Lecerf, V. Huch, S Hufner, R. Haberkorn, H. P. Beck, M. Jilavi, J. Am. Ceram. Soc. 2001, 84, 1921.

[11] J. F. Eichler, O. Just, W. S. Rees, J. Mater. Chem. 2004, 14, 3139.

[12] G. A. Seisenbaeva, E. V. Suslova, M. Kritikos, V. G. Kessler, L. Rapenne, M. Andrieux, F. Chassagneux, S. Parola, J. Mater. Chem. 2004, 14, 3150

[13] S. Mathur, M. Veith, R. Rapalaviciute, H. Shen, G. F. Goya, W. L. Martins, T. S. Berquo, Chem. Mater. 2004, 16, 1906.

[14] J. H. Thurston, T. O. Ely, D. Trahan, K. H. Whitmire, Chem. Mater. 2003, 15, 4407.

[15] H. O. Davies, A. C. Jones, T. J. Leedham, P. O’Brien, A. J. P. White, D. J. Williams, J. Mater. Chem. 1998, 8, 2315.

[16] C. L. Carnes, P. N. Kapoor, K. J. Klabunde, J. Bonevich, Chem. Mater. 2002, 14, 2922.

[17] M. Veith, S. Mathur, C. Mathur, Polyhedron 1998, 17, 1005.

[18] L. G. Hubert-Pfalzgraf, Coord. Chem. Rev. 1998, 180, 967.

[19] L. G. Hubert-Pfalzgraf, Inorg. Chem. Commun. 2003, 6, 102.

[20] Y. Ohno, D. K. Young, B. Beschoten, F. Matsukura, H. Ohno, D. D. Awschalom, Nature 1999, 402, 790.

[21] P. Ball, Nature 2000, 404, 918.

[22] M.-L. Tong, S.-L. Zheng, J.-X. Tong, H. K. Lee, X.-M. Chen, J. Chem. Soc. Dalton Trans. 2002, 124, 1727. 